\title{
Finding the force: a novel word learning experiment with modals
}

Anouk Dieuleveut, Ailís Cournane \& Valentine Hacquard*

\begin{abstract}
This study investigates the semantic and pragmatic challenges of acquiring the force of English modals, which express possibility (e.g., might) and necessity (e.g., must). Children seem to struggle with modal force through at least age 4, overaccepting both possibility modals where adults would prefer necessity modals, and necessity modals in possibility situations. These difficulties are typically blamed on pragmatic or conceptual immaturity. In this study, we sidestep these immaturity issues by investigating the challenges of modal learning through a novel word learning experiment with adults, for different 'flavors' of modals: epistemic (knowledge-based) versus teleological (goal-based), and comparing novel modals with actual English modals. We find that, when learning possibility modals, adult learners behave as expected: they accept novel modals in necessity situations, both in epistemic and teleological contexts, but less often after they have learned a pragmatically more appropriate necessity modal. However, when learning necessity modals, participants manage to learn the right force (i.e., reject them in possibility situations) for epistemic scenarios only; with teleological scenarios, they accept them in possibility situations. We propose that an overlap in modal flavor explains their behavior, specifically, the competition with an ability interpretation in teleological but not epistemic scenarios, which could also contribute to children's difficulty with necessity modals reported in the acquisition literature.
\end{abstract}

Keywords. modal force; modal flavor; novel word learning experiment; scalar implicatures

1. Introduction. English modals express either possibility (e.g., might in (1a)) or necessity (e.g., must in (1b)). ${ }^{1}$ When and how do children figure out the force of their modals, for instance, that might means 'possible', and must, 'necessary'? The previous acquisition literature shows that children struggle with modal force until at least age 4 . They both over-accept possibility modals in contexts where adults prefer necessity modals, and they over-accept necessity modals in possibility situations. These difficulties are typically blamed on pragmatic or conceptual immaturity: Their over-acceptance of possibility modals is blamed on difficulty computing implicatures, and failure to realize that necessity modal is often more appropriate in necessity situations (Noveck 2001; Ozturk and Papafragou 2015, a.o.). Their over-acceptance of necessity modals in possibility situations is blamed on difficulty reasoning about open possibilities (Ozturk and Papafragou 2015; see also Acredolo and Horobin 1987). In both cases, it is assumed that children know the force of the modals, but have difficulty using them. But, could children's over-acceptance of both possibility and necessity modals instead reflect a lack of knowledge of their underlying force? In this study, we investigate the semantic and pragmatic challenges of modal force acquisition beyond issues of

* We thank the members of UMD/NYU Modality group, S-Lab and Acquisition Lab, especially Alexander Williams, Jeff Lidz, as well as Floriane Dieuleveut for the materials. This research is supported by NSF grant \#BCS1551628. Authors: Anouk Dieuleveut, University of Maryland (adieulev@umd.edu); Ailís Cournane, New York University (cournane@nyu.edu) \& Valentine Hacquard, University of Maryland (hacquard@umd.edu).

${ }^{1}$ Further force distinctions can be made: in particular, necessity modals are often split into strong (must) vs. weak (should) necessity (von Fintel and Iatridou 2008). In this study, we focus on the main contrast between possibility and necessity. 
conceptual and pragmatic immaturity, by testing how adults learn novel modals, and what situations might be particularly challenging. Imagine a child hearing a new modal, sig, in (2). How does she determine whether sig means possible or necessary?
a. The keys might be in the drawer.
possibility
b. The keys must be in the drawer.
necessity

(2) The keys sig be in the drawer.

$?$

This mapping may be especially challenging for necessity modals, as modals give rise to a classic "subset problem" (Xu and Tenenbaum 2007; Piantadosi et al. 2013; Rasin and Aravind 2020, a.o.): necessity entails possibility. Thus, situations of necessity are also situations of possibility. If sig means possible, but children initially think it means necessary, they should have evidence that their hypothesis is wrong, as sig will be sometimes used in situations where a necessity is logically false (any situations of mere possibility). However, if sig means necessary, but children think it means possible, they may have no counterevidence that their hypothesis is too weak, as sig $p$ will only be used by speakers in situations where a possibility statement, might $p$, is also logically true. ${ }^{2}$

The child also needs to figure out how modals are used in conversation, and when the use of one is more appropriate than the other. English has both possibility and necessity modals, which form Horn scales (Horn, 1972). As such, they can give rise to scalar implicatures (SI) (Grice 1975; Horn 1972): for instance, the use of (1a) can implicate that it is not necessarily the case that the keys are in the drawer (not (must $p$ )). In the Gricean tradition, this implicature arises from the assumption that participants in a conversation are trying to be maximally informative: speakers should prefer to use must $p$ if it is relevant. Listeners can thus infer that it is not the case that the speaker believes the more informative (logically stronger) sentence (1b): not (must p). To make scalar implicatures, children need to know that their language has dual pairs, i.e., that <might, must>, similarly to <some, all>, form a Horn scale (Horn 1972). However, this is not the case in all languages: 'variable force' modals (i.e., modals that are used both in possibility and in necessity situations) have been described for several languages, and analyzed as underlying possibility modals (e.g., Nez Perce o'qa, Deal 2011; Gitksan =ima, Matthewson 2013; Peterson 2010) as well as underlyingly necessity modals (e.g., in St' at'imcets, Rullmann et al. 2008; in Washo, Bochnak 2015) (see Yanovich 2013 for a summary). This means that learners cannot expect their language to have modal duals. And even in a language with duals like English, knowing the force of one modal does not guarantee that the next modal expresses a different force, given that several lexemes can express the same force (e.g., can, might, may). Thus, to be able to know that a possibility modal is inappropriate in a necessity situation, the child needs to be aware of the existence (and underlying force) of an alternative necessity modal. Now imagine a child who has acquired possibility modals in her language, but has wrongly acquired possibility meanings for her necessity modals, because of the overlap in force (subset problem). This child should thus both accept necessity modals (which she believes express possibility) in possibility situations, and possibility modals in necessity situations (since she lacks a stronger dual). Such a mapping error with necessity modals could explain children's difficulties in previous studies.

${ }^{2}$ Unless children can use evidence from downward-entailing environments, which reverse patterns of entailment, as suggested for other subset problems (Gualmini and Schwarz 2009). However, it is unlikely that children can use such a strategy in the case of modals, given their input (see Dieuleveut et al. 2019, in prep, for discussion).

Anouk Dieuleveut, Ailís Cournane and Valentine Hacquard:

Finding the force: a novel word learning experiment with modals. 
We would like to highlight one last potentially complicating factor for force acquisition. In English, as in many other languages, the same modals can express different 'flavors', or types, of modality (Kratzer 1981, 1991): an epistemic (based on knowledge or evidence, as in (1a-b)), or various root modalities, like teleological (based on goals, and illustrated in (3a-b)), deontic (based on rules), bouletic (based on desires) or ability (based on capacities). The context typically helps determine what flavor is intended. But, from a learner's perspective it is important to note that these flavors are not mutually exclusive (e.g., it could both be likely and required for my keys to be the drawer). The force challenge could in principle be easier to resolve in some flavors than others. But the overlap in flavor raises a potential further challenge for force acquisition: could a necessity modal intended in one flavor be interpreted as a possibility modal in another flavor?

a. To get to the library, we can go down the yellow road. POSSIBILITY

b. To get to the library, we must go down the yellow road. NECESSITY

In this study, we investigate the semantic and pragmatic challenges of acquiring the force of modals, independent of conceptual or pragmatic immaturity, by using a novel word learning experiment with adults. Given the subset problem, how good are learners at figuring out force? Do learners accept novel modals learned in possibility contexts in necessity situations? Do they accept novel modals learned in necessity contexts in possibility situations? What is the effect of knowing a scalemate? And finally, do we find differences between flavors, here epistemic vs. teleological?

Our results show that when learning possibility modals, adult learners behave as expected: they accept novel modals in necessity situations, but less so after they have learned a pragmatically more appropriate necessity modal, both in epistemic and teleological contexts. However, when learning necessity modals, participants manage to learn the right force (rejecting them in possibility situations) only for epistemic scenarios. With teleological scenarios, they do not learn necessity modals, and accept them in possibility situations. We propose that their behavior in teleological scenarios can be explained by an overlap in flavor, specifically, the competition with an ability interpretation. We relate this finding to children's reported difficulty with necessity modals in the acquisition literature, and argue that overlap in flavor (here, teleological and ability) might be more of a problem than overlap in force (possibility and necessity) for modal force acquisition.

2. Study. In this study, we test how adults learn novel modals, by introducing them to a fictional dialect of English. They are taught modals either in possibility contexts (where it is clear that more than one option is open) or necessity contexts (where it is clear than there is just a single option), and then have to judge whether that modal is appropriate in necessity or possibility situations. We investigate how being taught a scale-mate in a second round of learning affects their judgments (e.g., they should be more reluctant to accept a possibility modal in a necessity situation if they've previously learned a necessity modal), and whether their judgements vary as a matter of flavor (we tested both teleological and epistemic scenarios, between subjects).

2.1. Procedure. Participants were introduced to Luke, who is learning new words from a (fictional) foreign dialect, Kabberton English, from a native-speaker, Mary. ${ }^{3}$ All participants learned 3 novel words in blocks. Word 1 was a control (frimp 'to grab'). Words 2 \& 3 varied between

\footnotetext{
${ }^{3}$ Examples of the experiments (for epistemic and teleological conditions) can be accessed below: Kabberton experiment epistemic: http://spellout.net/ibexexps/AD/kab_sg_eNeP_G_2/experiment.html teleological: http://spellout.net/ibexexps/AD/kab_sg2_tPtN_S_1/experiment.html epistemic: http://spellout.net/ibexexps/AD/kab_mod_eNeP_S_1/experiment.html teleological: http://spellout.net/ibexexps/AD/kab_mod2_tNtP_S_2/experiment.html
}

Anouk Dieuleveut, Ailís Cournane and Valentine Hacquard:

Finding the force: a novel word learning experiment with modals. 
subjects, either a novel possibility modal first (learned in POSSIBILITY situations, tested in NECESSITY situations), or a novel necessity modal first (learned in NECESSITY, tested in POSSIBILITY), followed by a block with the other modal. For all words, participants first saw Mary use the word (Training 1: 4 items), then Luke (Training 2: 4 yes-control, 4 no-control, with feedback), then the test phase (Test: 6 trials, 6 yes-control, 6 no-control, no feedback). Participants had to judge whether Luke's use of the word was correct, by choosing between 'Yes, that's correct' and 'No, that's not correct.' Figure 1 illustrates POSSIBILITY, NECESSITY and IMPOSSIBILITY situations by flavor, with test sentences (4). ${ }^{4}$ Figure 2 summarizes the procedure. We ran an identical experiment with English modals as a control, testing might/must (epistemic flavor) and can/must (teleological flavor). The only difference was in the instructions: in the English version, Luke was from Kabberton, and was learning English with Mary. Experiments were run on Alex Drummond's IBEX Farm. At the end of the Novel Word experiment, participants were asked to provide translations. We tested Flavor (teleological vs. epistemic) between subjects and Force (possibility vs. necessity) within. Participants saw either a necessity modal first or a possibility modal. Conditions are summarized in (5). Details of the instructions are given in the Appendix.

(4) epistemic: Kabberton: 'The keys sig/gleeb be in the [blue] box.'

English (Control): 'The keys might/must be in the [blue] box.'

teleological: Kabberton: 'We sig/gleeb go down the [blue] road.'

English (Control): 'We can/must go down the [blue] road.'

(5) Experiment: Kabberton (Novel Word) vs. English (Control) (between subjects)

Flavor: epistemic vs. teleological

Force: $\quad$ possibility modal vs. necessity modal (between subjects)

Order: learnt first vs. second (i.e., knowing a dual)

(within subjects)

(between subjects)

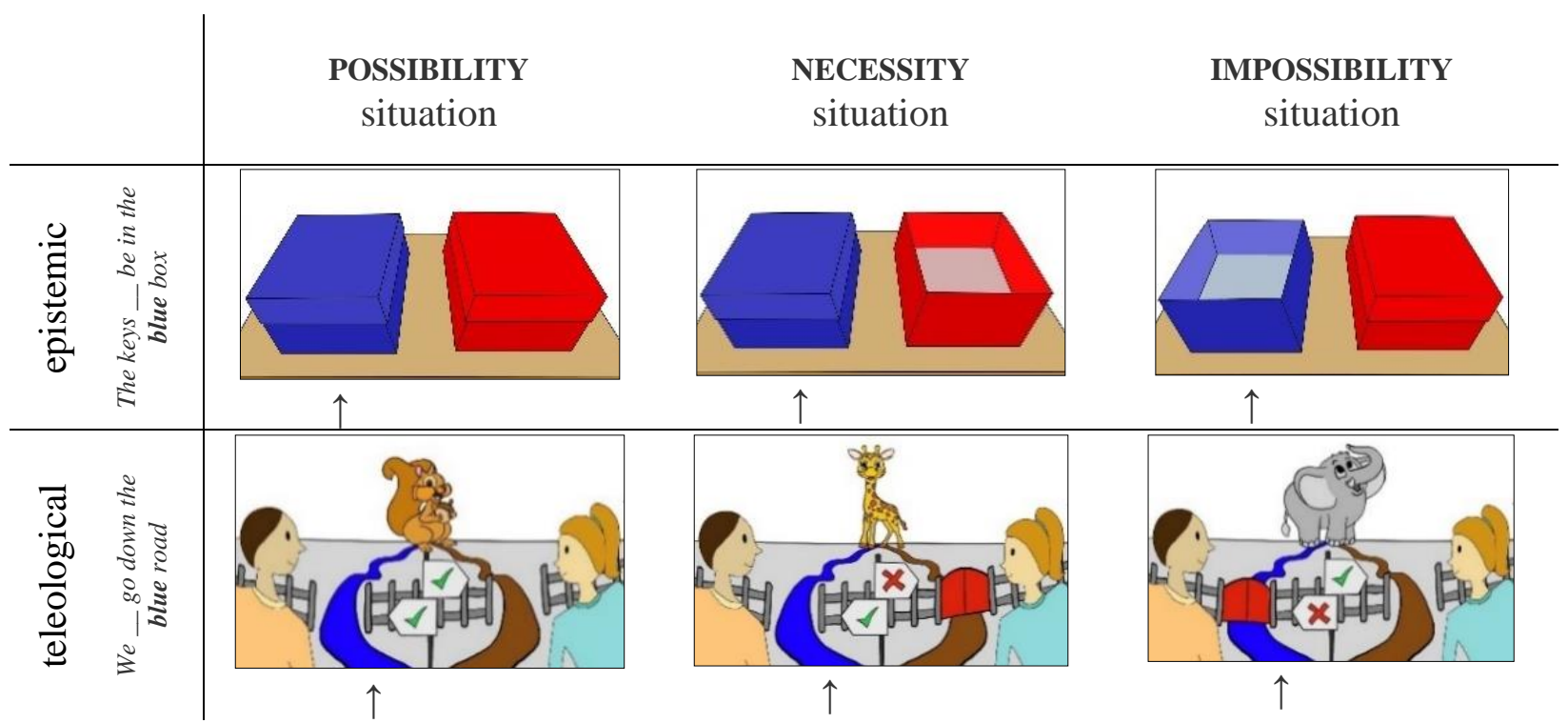

Figure 1. Visual stimuli and test sentence frames, for epistemic and teleological conditions, by situation type

\footnotetext{
${ }^{4}$ No-controls always corresponded to IMPOSSIBILITY situations, regardless of the force of the modal learnt.
} 


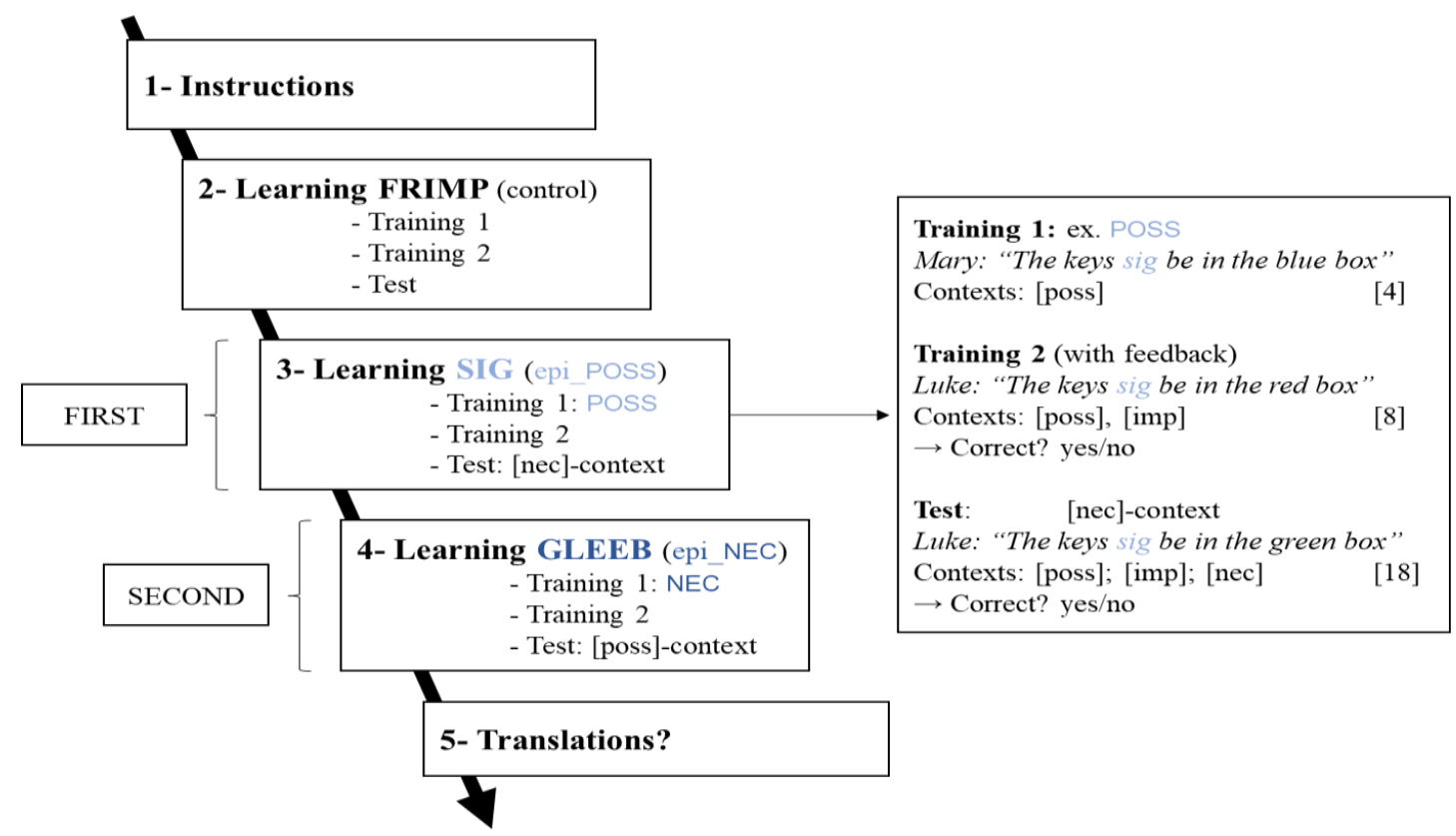

Figure 2. Experimental procedure: Novel Word (Kabberton) experiment in the epistemic condition, with block order: control, possibility, necessity.

2.2. EXPECTATIONS. English experiment. Participants should reject possibility modals (might/can) in NECESSITY situations if they assume an SI, and accept them if they do not (literal interpretation). They should reject necessity modals (must) in POSSIBILITY situations. Kabberton experiment. When learning a novel modal in POSSIBILITY contexts, participants should accept it in NECESSITY situations, unless they previously learned a stronger dual. When learning a novel modal in NECESSITY contexts, participants should reject it in POSSIBILITY situations, if they learned it as a necessity modal, but accept it if they learned it as a possibility modal.

2.3. PARTICIPANTS. 386 U.S. English participants were recruited on Amazon MT (Kabberton experiment, $\mathrm{n}=194$ (97 female, age $m=37 \mathrm{yrs}$ ); English experiment: $\mathrm{n}=192$ (97 female, age m=38yrs); after exclusion on controls (3.4\%): 373 participants (Kabberton: 188, English: 185).

2.4. RESUlts. Data analyses were conducted using R (R Core Team, 2013), using the package lme4 (Bates et al., 2014a, 2014b). We used binomial linear mixed effects models, built with a maximal random effect structure based on subjects and items as random variables, even though we sometimes had to step back to random intercepts only models when the model failed to converge with the full random effects specification (following Barr et al.). ${ }^{5}$ Figure 3 shows proportion of yes responses on test trials for both Kabberton and English experiments, depending on block order and flavor, for possibility and necessity modals. Test trials for possibility modals correspond to NECESSITY situations (red bars), and to POSSIBILITY situations (yellow bars) for necessity modals. Table 1 reports the mean proportion of yes answers (with standard error) on POSSIBILITY and NECESSITY situations, depending on order and flavor. Analysis. The error rate on controls was very low (Kabberton: 3.3\%; English: $2.8 \%$ ). In the English version of the experiment, we find a relatively low rate of Scalar Implicatures, especially in the teleological condition (yes answers in NECESSITY: epistemic might: 90.4\%; teleological can: 97.9\%). Participants correctly reject

\footnotetext{
5 These cases are indicated with FTC (for "Failure to Converge") in Tables 2 and 3.
} 
necessity modals in POSSIBILITY situations, for both flavors (epistemic must: $13.0 \%$; teleological must: 19.9\%). In the Novel Word experiment, we find that participants accept novel possibility modals in NECESSITY contexts at high rates for both epistemic $(81.5 \%)$ and teleological $(98.6 \%)$ modals, with no difference with the English controls might/can (Table 2). However, when they learn necessity modals, we find an unexpected difference between flavors. Participants correctly learn a necessity modal in the epistemic condition (they accept it in POSSIBILITY at only 23.6\%, with no significant difference with English might). But they do not seem to learn the necessity modal as necessity in the teleological condition, and accept it $77.2 \%$ in POSSIBILITY situations, with a significant difference with the English control (Kabberton vs. English: $\chi 2(1)=77.9, p$ $<.0001 * * *$ ), suggesting they have learned a possibility modal (Table 2). Effect of Order. For possibility modals, we find a significant effect of order in both experiments: they are accepted less often when learned second, i.e., when subjects know a scale-mate (Novel Word: epistemic: 46.4\%; teleological: 64.3\%; English: might: 47.1\%; can: 87.2\%) (Table 3). However, for necessity modals we again find a difference between epistemic and teleological flavors: there is no significant effect for epistemics, and for teleologicals, the effect goes in the opposite direction for the Kabberton and the English experiments (decrease for Kabberton, increase for English), with a highly significant interaction effect.

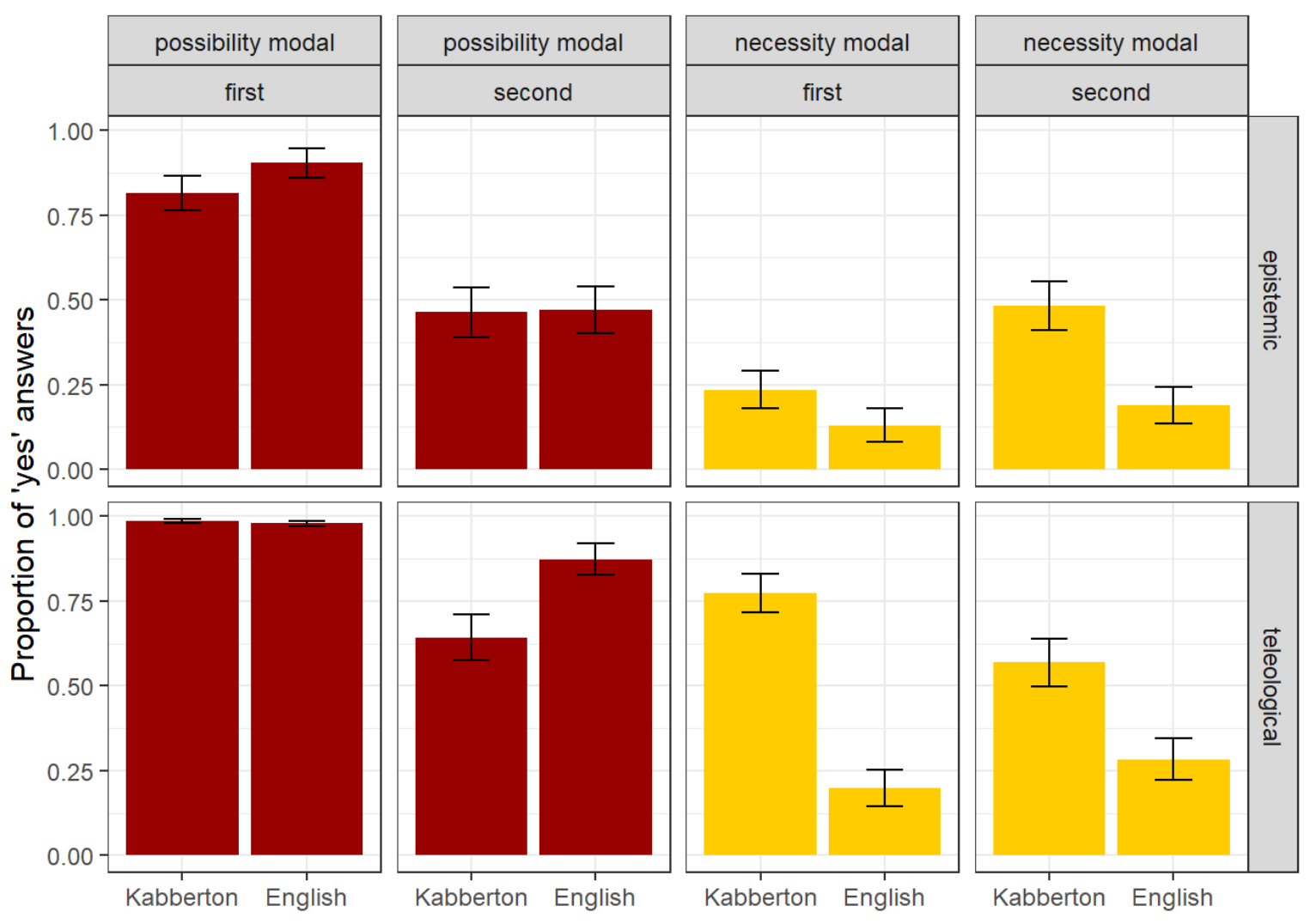

Figure 3. Proportion of yes responses for possibility and necessity modals in NECESSITY (red) and POSSIBILITY (yellow) situations, faceted for force (possibility, necessity), order (1st, 2nd) and flavor (Epistemic, Teleological) (Epistemic: Kabberton: $n=91$ participants *6 observations, English: n=91*6; Teleological: Kabberton: $n=97 * 6$, English: $n=96 * 6$ ). 


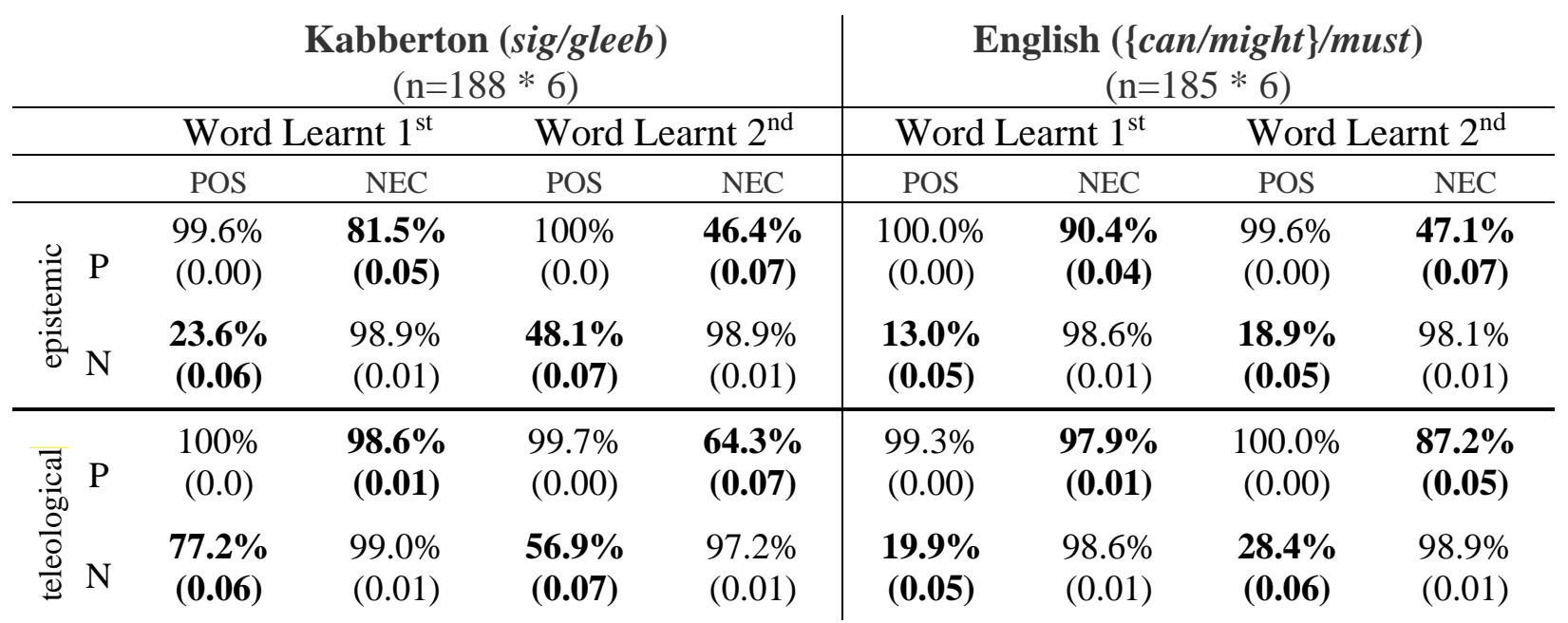

Table 1. Proportion of yes answers (standard error in parentheses) on POSSIBILITY (P) and NECESSITY (N) situations for possibility and necessity modals, depending on order and flavor, for the Kabberton ( $\mathrm{n}=188$ participants*6 observations) and the English experiments ( $\mathrm{n}=185$ participants $* 6$ observations). Bold cells correspond to test cases. Accuracy on no-controls (IMPOSSIBILITY) was very high, with no difference between groups, so we don't report here.

\begin{tabular}{|c|c|c|}
\hline & Word Learnt $1^{\text {st }}$ & Word Learnt $2^{\text {nd }}$ \\
\hline Epistemic possibility & $\begin{array}{l}\text { FTC with full specification } \\
\chi^{2}(1)=0.20, p=0.65\end{array}$ & $\chi^{2}(1)=2.2, p=0.14$ \\
\hline Epistemic necessity & $\chi^{2}(1)=3.23, p=0.072$ & $\chi^{2}(1)=0.91, p=0.34$ \\
\hline Teleological possibility & $\begin{array}{l}\text { FTC with full specification } \\
\chi^{2}(1)=0.46, p=0.50\end{array}$ & $\chi^{2}(1)=0.55, p=0.46$ \\
\hline Teleological necessity & $\chi^{2}(1)=77.9, p<2 e-16^{* * * *}$ & $\chi^{2}(1)=25.9, p=4 e-07 * * *$ \\
\hline
\end{tabular}

Table 2. Comparison between Kabberton and English experiment test conditions, for epistemic and teleological possibility and necessity modals.

\section{Kabberton Experiment English Experiment}

\begin{tabular}{lll}
\hline $\begin{array}{l}\text { Epistemic possibility } \\
\text { (tested in NECESSITY) }\end{array}$ & $\begin{array}{l}F T C \text { with full specification } \\
\chi^{2}(1)=21.4, p=3.7 e-06 * *\end{array}$ & $\chi^{2}(1)=8.1, p=0.004 * *$ \\
\hline $\begin{array}{l}\text { Epistemic necessity } \\
\text { (tested in POSSIBILITY) }\end{array}$ & $\chi^{2}(1)=1.37, p=0.24(N S)$ & $\chi^{2}(1)=0.13, p=0.71(N S)$ \\
\hline $\begin{array}{l}\text { Teleological possibility } \\
\text { (tested in NECESSITY) }\end{array}$ & $\begin{array}{l}F T C \text { with full specification } \\
\chi^{2}(1)=10, p=0.0015 * *\end{array}$ & $\chi^{2}(1)=23.5, p=1.24 e-06 * * *$ \\
\hline $\begin{array}{l}\text { Teleological necessity } \\
\text { (tested in POSSIBILITY) }\end{array}$ & $\chi^{2}(1)=36, p=2 e-09 * * *$ & $\chi^{2}(1)=38.9, p=4.34 e-10 * * *$
\end{tabular}

Table 3. Results of models testing effect of knowing a dual for possibility and necessity epistemic and teleological modals on test conditions for the Kabberton and English experiments. 
2.5. TRAnSLAtiOnS. At the end of the Novel Word experiment, participants were asked to provide translations. Table 4 summarizes their answers, by flavor and force. Grey cells correspond to accurate translations. We see that possibility modals are overall correctly identified more often than necessity modals. Necessity teleological modals are quite often translated with possibility modals $(21 \%)$, but epistemic modals are not $(8 \%)$. Epistemic necessity modals are quite often translated with $b e$; teleological modals with verbs.

\begin{tabular}{ccccccc} 
& P modal & N modal & be & will & verb & other \\
\hline \multirow{2}{*}{$\mathrm{P}$} & $78 \%$ & $4 \%$ & $4 \%$ & $0 \%$ & $0 \%$ & $14 \%$ \\
$\mathrm{~N}$ & $8 \%$ & $48 \%$ & $\mathbf{2 9 \%}$ & $3 \%$ & $0 \%$ & $11 \%$ \\
\hline \multirow{2}{*}{$\mathrm{P}$} & $63 \%$ & $8 \%$ & $0 \%$ & $2 \%$ & $11 \%$ & $18 \%$ \\
$\mathrm{~N}$ & $\mathbf{2 1 \%}$ & $53 \%$ & $0 \%$ & $3 \%$ & $11 \%$ & $14 \%$
\end{tabular}

Table 4. Translations for sig/gleeb (Kabberton Experiment). Considered as possibility modals: can, could, may, might, allow, be able; as necessity modals: must, have to, should; other: no answer, I don't remember; nonsense words.

3. Discussion. We find that adult learners accept novel possibility modals in new necessity situations at high rates, for both epistemic and teleological flavors. This suggests that they correctly learn them as possibility modals: they behave as Nez-Perce speakers, who lack a stronger scalemate in their language that would be more appropriate (Deal 2011; see also Ozturk \& Papafragou, 2015). We find a significant effect of having learned a scale-mate, again for both epistemic and teleological flavors: novel possibility modals are accepted less often once learners know that there is another word in the lexicon to describe NECESSITY situations. Learners thus make scalar implicatures with novel words.

Turning to novel necessity modals, we find an (unexpected) difference between epistemic and teleological scenarios. In the epistemic condition, learners correctly learn novel necessity modals: they accept them in possibility situations at only $23.6 \%$, with no significant difference with English must $(13.0 \%)$. But in the teleological condition, the rate of rejection is much lower: most participants accept them in possibility situations (77\%), with a highly significant difference with English can $(19.9 \%)$, suggesting that they have learnt a possibility modal despite being exposed to the novel modal only in NECESSITY situations in the learning phase. Why do participants accept novel necessity modals in teleological possibility situations? And how can we explain the difference between epistemic and teleological conditions?

Participants' behavior in the teleological condition might come from differences in perspectives between the learner and the experimenter: participants might not interpret our (intended) teleological necessity situations as such. These scenarios make an ability interpretation salient: the question of whether it is 'possible or not' to go down the yellow road might be more salient than whether it is 'possible or necessary' to use this road to get to their goal. A competition with an ability interpretation would also explain the ceiling acceptance rate found for English can in those scenarios $\left(98.6 \%\right.$ when learned $\left.1^{\text {st }}\right)$, and the fact that participants do not make scalar implicatures: they do not seem to consider 'we must go down the yellow road' as a more relevant sentence to use. Potentially reinforcing this, regardless of whether they were learning a possibility or a necessity modal, participants were trained on IMPOSSIBILITY situations: this might have indirectly manipulated the QUD, and increased the contrast possible/impossible.

This result opens up a new possibility for what might make modal force acquisition challenging for children. If children tend to interpret situations where parents intend a teleological necessity as ability, they could lexicalize a possibility meaning for necessity modals. This could explain their 
difficulties reported in the acquisition literature: both results from comprehension experiments, where children are found to over-accept necessity modals in - intended - possibility situations (e.g., Noveck 2001; Ozturk and Papafragou 2015), and results from corpus studies with younger children, which show that 2-year-olds use necessity modals in situations where adults expect possibility modals (Dieuleveut et al. 2019). In epistemic scenarios, the same problem may not arise (at least in our scenarios), as competition with an ability interpretation is less likely. ${ }^{6}$

4. Conclusion. In this study we have addressed semantic and pragmatic factors that may affect modal force learning, using a Novel Word paradigm with adult English speakers. Through studying adult learners, we aim to better understand why child learners struggle with modal force. Does their non-adult-like behavior come from conceptual issues, from semantic issues (not having lexicalized the right force, either assuming necessity meanings for might, or possibility meaning for must), or does it come from pragmatics (not making scalar implicatures, i.e. not considering necessity alternatives as relevant when adults would)? Our study with adults, who have mature conceptual and pragmatic abilities, suggest that children's struggles could also be due to problems interpreting flavor correctly, rather than an issue with force per se, nor with implicatures. Our results thus highlight the importance of taking into account flavor variability to understand the source of children's struggles with force reported in the acquisition literature.

\section{References}

Acredolo, C., \& Horobin, K. (1987). Development of relational reasoning and avoidance of premature closure. Developmental Psychology,23(1), $\quad 13 . \quad$ https://doi.org/10.1037/00121649.23.1.13

Barr, D. J., Levy, R., Scheepers, C., \& Tily, H. J. (2013). Random effects structure for confirmatory hypothesis testing: Keep it maximal. Journal of Memory and Language, 68(3), 255-278. https://doi.org/10.1016/j.jml.2012.11.001

Bates, D., Mächler, M., Bolker, B., \& Walker, S. (2014). Fitting linear mixed-effects models using lme4. arXiv preprint arXiv:1406.5823. https://doi.org/10.18637/jss.v067.i01

Bochnak, M. R. (2015). Variable force modality in Washo. In Proceedings of North-East Linguistics Society (Vol. 45, pp. 105-114).

Deal, A. R. (2011). Modals without $\quad$ scales. Language, 87(3), 559-585. https://doi.org/10.1353/lan.2011.0060

Dieuleveut, A., van Dooren, A., Cournane, A., \& Hacquard, V. (2019). Acquiring the Force of Modals: Sig You Guess What sig Means?.

Grice, H. P., Cole, P., \& Morgan, J. L. (1975). Logic and conversation. 1975, 41-58. https://doi.org/10.1163/9789004368811_003

Gualmini, A., \& Schwarz, B. (2009). Solving learnability problems in the acquisition of semantics. Journal of Semantics, 26(2), 185-215. https://doi.org/10.1093/jos/ffp002

Horn, L. R. (1972). On the semantic properties of logical operators. Doctoral dissertation, UCLA. Kratzer, A. (1981). Partition and revision: The semantics of counterfactuals. Journal of Philosophical Logic, 10(2), 201-216. https://doi.org/10.1007/bf00248849

${ }^{6}$ What makes the ability reading more salient in the teleological case is that a prerequisite for a teleological necessity is that it be circumstantially possible, but this circumstantial possibility is not trivial, so scenarios of teleological necessities necessarily might involve considerations of circumstantial ability. In epistemic necessity scenarios, circumstantial possibility may be more trivially satisfied, and hence not as relevant.

Anouk Dieuleveut, Ailís Cournane and Valentine Hacquard:

Finding the force: a novel word learning experiment with modals. 
Kratzer, A. (1991). Modality. Semantics: An international handbook of contemporary research, 7 , 639-650. https://doi.org/10.1515/9783110842524-004

Matthewson, L. (2013). Gitksan modals. International Journal of American Linguistics, 79(3), 349-394. https://doi.org/10.1086/670751

Noveck, I. A. (2001). When children are more logical than adults: Experimental investigations of scalar implicature. Cognition, 78(2), 165-188. https://doi.org/10.1016/s0010-0277(00)001141

Ozturk, O., \& Papafragou, A. (2015). The acquisition of epistemic modality: From semantic meaning to pragmatic interpretation. Language Learning and Development, 11(3), 191-214. https://doi.org/10.1080/15475441.2014.905169

Peterson, T. R. G. (2010). Epistemic modality and evidentiality in Gitksan at the semantics-pragmatics interface. Doctoral dissertation, University of British Columbia.

Piantadosi, S. T., Tenenbaum, J. B., \& Goodman, N. D. (2013). Modeling the acquisition of quantifier semantics: a case study in function word learnability. Under review.

Rasin, E., \& Aravind, A. (2020). The nature of the semantic stimulus: the acquisition of every as a case study. Natural Language Semantics, 1-37. https://doi.org/10.1007/s11050-020-091686

Rullmann, H., Matthewson, L., \& Davis, H. (2008). Modals as distributive indefinites. Natural Language Semantics, 16(4), 317-357. https://doi.org/10.1007/s11050-008-9036-0

Searle, J. R. (1969). Speech acts: An essay in the philosophy of language (Vol. 626). Cambridge University Press. https://doi.org/10.1017/CBO9781139173438

Team, R. C. (2013). R: A language and environment for statistical computing.

Von Fintel, K., \& Iatridou, S. (2008). How to say Ought in foreign: The composition of weak necessity modals. In Time and modality (pp. 115-141). Springer, Dordrecht. https://doi.org/10.1007/978-1-4020-8354-9_6

$\mathrm{Xu}, \mathrm{F} .$, \& Tenenbaum, J. B. (2007). Word learning as Bayesian inference. Psychological Review, 114(2), 245. https://doi.org/10.1037/0033-295x.114.2.245

Yanovich, I. (2016). Old English *motan, variable-force modality, and the presupposition of inevitable actualization. Language, 92(3), 489-521. https://doi.org/10.1353/lan.2016.0045

\section{Appendixes}

INSTRUCTIONS.

Kabberton experiment

Luke and Mary are friends. For the holidays, they are going to Kabberton, the country Mary is from. The language spoken in Kabberton is a lot like English, but some of the words are different, so before going, Mary is going to teach some Kabberton words to Luke. Your goal is to help Luke learn these words.

You are going to learn 3 new words, one after the other.

For each word, you will first see Mary using the word in diverse situations. The sentences Mary says are always correct, because she speaks Kabberton fluently.

Then, it will be Luke's turn to use the words. Your task will be to indicate whether Luke uses the words correctly or not. Be careful, Luke sometimes makes mistakes! 


\section{English experiment}

Luke and Mary are friends. They live in a country called Kabberton. For the holidays, they are going to the US, the country Mary is originally from. Luke is not from the United States, so he doesn't know some English words, and Mary is going to teach him some. Your goal is to help Luke learn these words.

You are going to help him with 3 new words, one after the other.

For each word, you will first see Mary using the word in diverse situations. The sentences Mary says are always correct, as she speaks English fluently.

Then, it will be Luke's turn to try to use the words. Your task will be to indicate whether Luke uses the words correctly or not. Be careful, he sometimes makes mistakes! 